Document downloaded from:

http://hdl.handle.net/10251/99484

This paper must be cited as:

Figueres Amorós, E.; Garcerá, G.; Sandia Paredes, J.; González Espín, FJ.; JESUS CALVO RUBIO (2009). Sensitivity Study of the Dynamics of Three-Phase Photovoltaic Inverters With an LCL Grid Filter. IEEE Transactions on Industrial Electronics. 56(3):706-717. doi:10.1109/TIE.2008.2010175

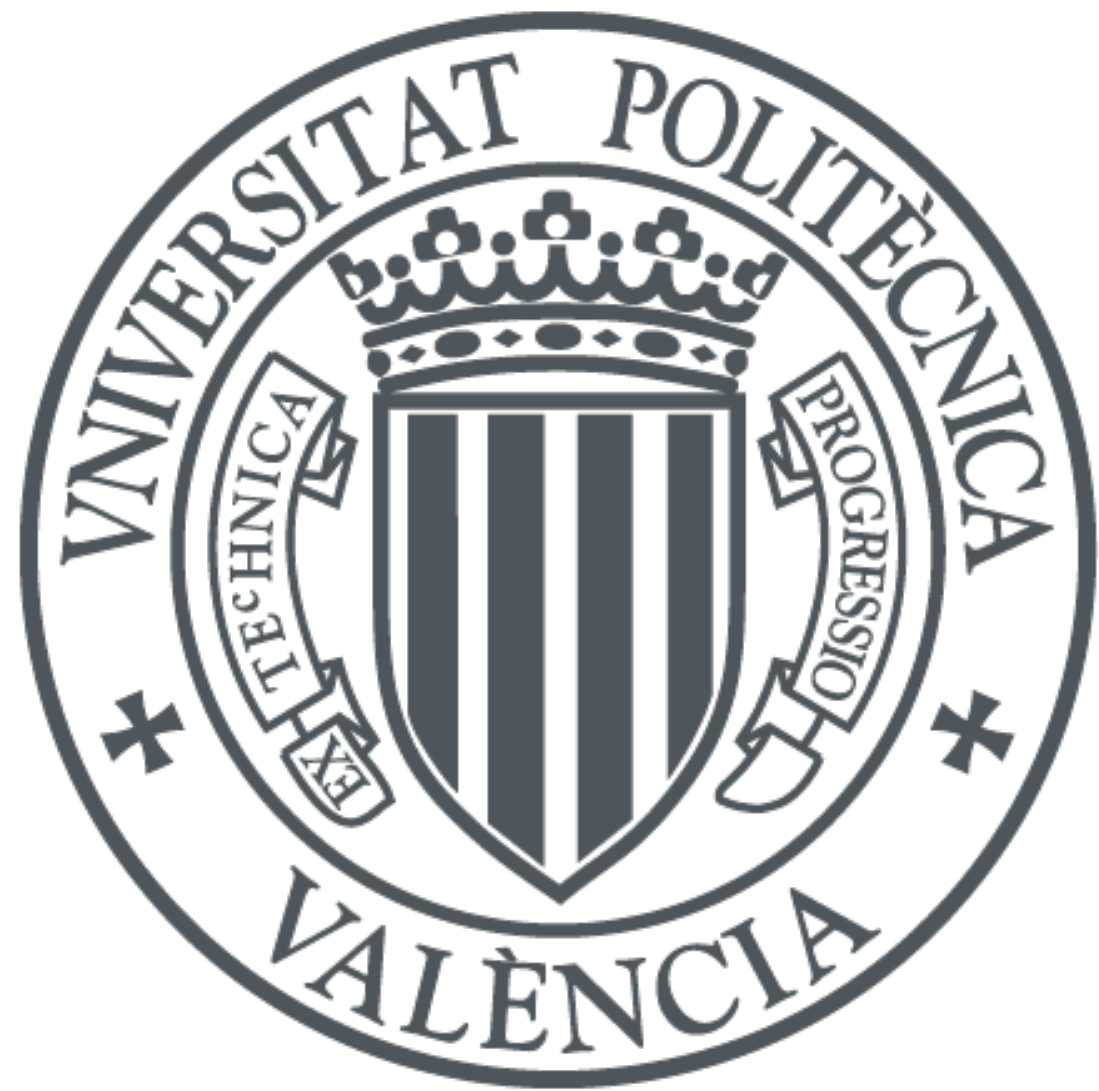

The final publication is available at

https://doi.org/10.1109/TIE.2008.2010175

Copyright Institute of Electrical and Electronics Engineers

Additional Information 


\title{
Sensitivity Study of the Dynamics of Three phase Photovoltaic Inverters with an LCL Grid Filter
}

\author{
Emilio Figueres, Member, IEEE, Gabriel Garcerá, Member, IEEE, Jesús Sandia, Fran González- \\ Espín, Student Member, IEEE, and Jesús Calvo
}

\begin{abstract}
An accurate small signal model of three phase photovoltaic inverters with a high order grid filter is derived in this paper. The proposed model takes into account the influence of both the inverter operating point and the PV panels characteristics on the inverter dynamic response. A sensitivity study of the control loops to variations of the dc voltage, the PV panels transconductance, the supplied power, and the grid inductance is performed using the proposed small-signal model. Analytical and experimental results carried out on a $100 \mathrm{~kW}$ photovoltaic inverter are presented.
\end{abstract}

Index Terms - Renewable energies, modeling and control of power inverters, distributed generation

\section{INTRODUCTION}

$\mathrm{P}$ HOTOVOLTAIC (PV) power generation is a concept of increasing interest. In the last years, a high number of photovoltaic farms with a power capacity up to some MW have appeared in the distributed power generation scenario. In order to disturb the distribution grid as little as possible, the switching harmonics generated by the power inverters must be properly filtered out, reaching a compromise between the cost and the weight of the filter, and fulfillment of international standards regarding the grid connection of power converters, like IEC/EN 61000-3-4 [1] and IEEE 15471 [2]. Such a compromise often requires the use of high order grid filters, typically in LCL configuration. However, the stability of the system may be compromised by the resonances of the LCL filter, so that a careful design of both the filter and the control strategy is mandatory. Several authors have recently studied theses issues in the case of grid connected converters [3]-[9], [28], and also in stand alone applications [10]. In [11]-[14] some control techniques to actively damp the resonances of the filter have been presented. However, in certain cases the active damping techniques need a high number of sensors; in other cases, they are sensitive to the filter tolerances or changes of the grid impedance. The inverter synchronization with the grid is a relevant problem that has been studied in

Manuscript received Feb 29, 2008. Accepted for publication October 14, 2008. Copyright (c) 2009 IEEE. Personal use of this material is permitted. However, permission to use this material for any other purposes must be obtained from the IEEE by sending a request to pubs-permissions@ieee.org.

E. Figueres (e-mail: efiguere@eln.upv.es), G. Garcerá, J. Sandia and Fran Gonzalez Espín are with Departamento de Ingeniería Electrónica, Universidad Politecnica de Valencia. J. Calvo is with Siliken Electronics, S.L.
[15]-[18], showing that Phase Locked Loops (PLL) based on the transformation of the grid voltages to a synchronous reference frame are currently a very interesting alternative to achieve that objective. The power production capability of the generation system is another issue that merits special attention, because the exploitation benefits of a photovoltaic farm intimately depend on the capability of the inverter to extract the maximum available power that can be instantaneously extracted from the panels. To achieve this relevant objective, a high number of Maximum Power Point Tracking (MPPT) techniques have been proposed in the past. Some of the most recent ones may be found in [19]-[23], [29][32]. A preliminary version of this paper [24] presents a study of the dynamic response of a $100 \mathrm{~kW} \mathrm{PV}$ inverter with an LCL grid filter. With regard to that preliminary version, the following novelties have been added in this paper: 1) a detailed derivation of the proposed small-signal model, which includes the dynamics of the PV panels around a maximum power point of their $I-V$ characteristics; 2 ) a sensitivity study of the control loops to variations of the dc voltage, the generated power, the grid inductance and the PV panels transconductance; and 3) new experimental results focused on the validation of the proposed small-signal model.

\section{Modeling AND CONTROL OF Three PHASE PV INVERTERS}

\section{A. Averaged model}

Fig. 1 shows the scheme of a three-phase Voltage Source Inverter (VSI) connected to the grid through an LCL filter. The series resistances of the inductors have been neglected, whereas a set of damping resistors, $R_{d}$, in series with the filter capacitors have been taken into account. Fig. 2 shows an averaged model of each one of the inverter branches, which may be obtained by neglecting the high frequency components of both the $d c$ voltage and the $a c$ phase currents [25]. In Fig. $2, d_{\phi}(\phi=a, b$, and $c)$ is the duty cycle of the upper switch of the inverter leg in a switching period, whereas $\bar{v}_{\phi}$ and $\bar{i}_{\phi}$ denote the average value in a switching period of the voltage across the lower switch, and of the ac current, respectively. By averaging the inverter legs in the scheme presented in Fig. 1 , the whole averaged model of the inverter in the stationary three-phase frame may be obtained, as shown by Fig. 3. From this scheme, the set of equations (1)-(4) are derived. 


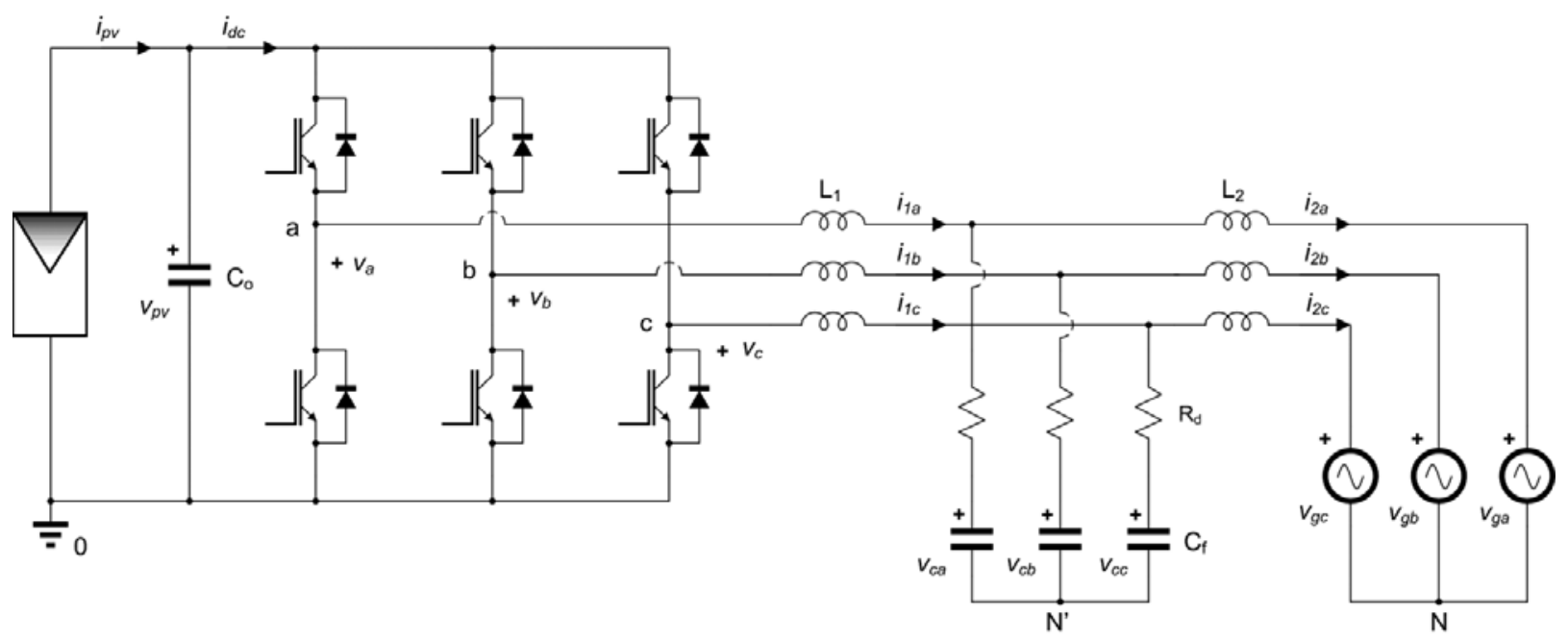

Fig. 1. Scheme of a VSI photovoltaic inverter with LCL grid filter.
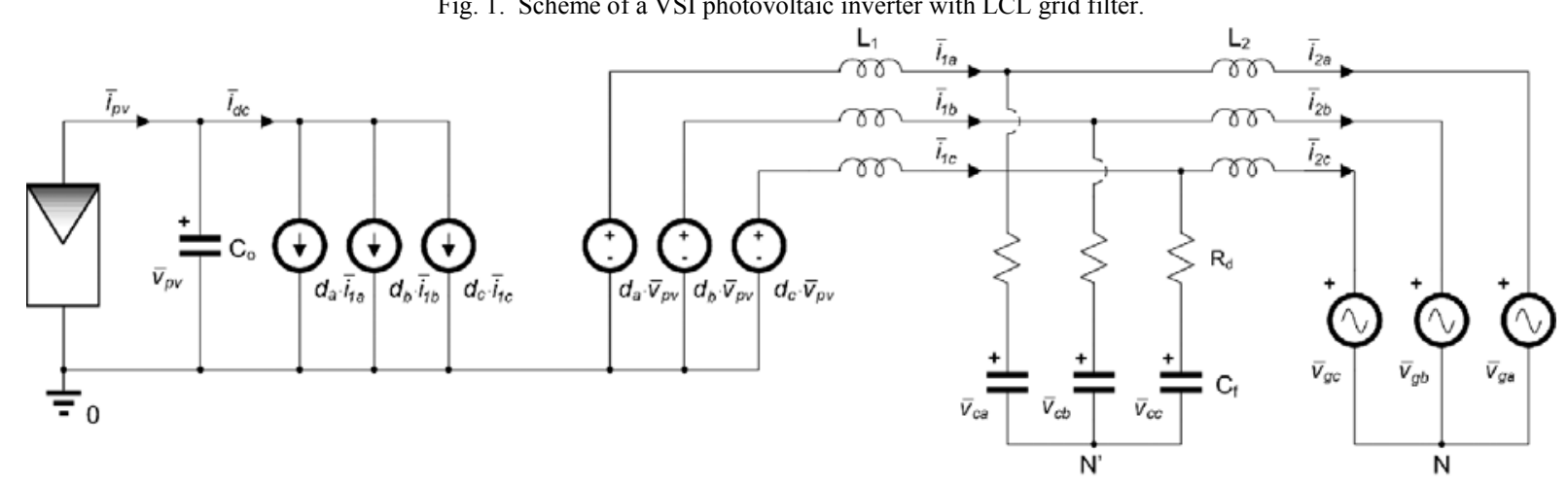

Fig. 3. Averaged equivalent circuit in the three phase stationary frame of a grid connected VSI photovoltaic inverter with LCL filter.

The set of equations (1)-(4) may be transformed into a synchronous $d q o$ reference frame multiplying them by the transformation matrix, T, following (5) and (6). In (5), $\omega$ denotes the grid angular frequency. In (6), $x$ stands for any of the circuit averaged variables.

$$
\begin{aligned}
& \frac{d}{d t}\left[\begin{array}{l}
\overline{i_{1}} \\
\overline{\dot{i}_{1}} \\
\overline{\dot{i}_{1 c}}
\end{array}\right]=-\frac{R_{d}}{L_{1}}\left[\begin{array}{l}
{\overline{i_{1}}}_{\overline{i_{1}}} \\
\overline{\dot{i}_{1 c}}
\end{array}\right]+\frac{R_{d}}{L_{1}}\left[\begin{array}{l}
{\overline{i_{2}}}_{2 a} \\
{\overline{i_{2}}}_{2 b} \\
\bar{i}_{2 c}
\end{array}\right]-\frac{1}{L_{1}}\left[\begin{array}{l}
\bar{v}_{c a} \\
\bar{v}_{c b} \\
\bar{v}_{c c}
\end{array}\right] \\
& +\frac{\bar{v}_{p v}}{L_{1}}\left[\begin{array}{l}
d_{a} \\
d_{b} \\
d_{c}
\end{array}\right]-\frac{\bar{v}_{N^{\prime}}}{L_{1}}\left[\begin{array}{l}
1 \\
1 \\
1
\end{array}\right] \\
& \frac{d}{d t}\left[\begin{array}{l}
{\overline{i_{2}}}_{2 a} \\
\overline{\dot{i}_{2 b}} \\
\overline{\dot{i}_{2 c}}
\end{array}\right]=\frac{R_{d}}{L_{2}}\left[\begin{array}{l}
\bar{i}_{1 a} \\
\overline{\dot{i}_{1 b}} \\
\overline{\dot{i}_{1 c}}
\end{array}\right]-\frac{R_{d}}{L_{2}}\left[\begin{array}{l}
{\overline{i_{2}}}_{\overline{\dot{i}_{2}}} \\
\overline{\dot{i}_{2 c}}
\end{array}\right]+\frac{1}{L_{2}}\left[\begin{array}{l}
\bar{v}_{c a} \\
\bar{v}_{c b} \\
\bar{v}_{c c}
\end{array}\right] \\
& -\frac{1}{L_{2}}\left[\begin{array}{c}
\bar{v}_{g a} \\
\bar{v}_{g b} \\
\bar{v}_{g c}
\end{array}\right]-\frac{\bar{v}_{N}-\bar{v}_{N^{\prime}}}{L_{2}}\left[\begin{array}{l}
1 \\
1 \\
1
\end{array}\right]
\end{aligned}
$$

$$
\begin{aligned}
& \frac{d}{d t}\left[\begin{array}{l}
\bar{v}_{c a} \\
\bar{v}_{c b} \\
\bar{v}_{c c}
\end{array}\right]=\frac{1}{C_{f}}\left(\left[\begin{array}{l}
\overline{i_{1 a}} \\
\overline{i_{1 b}} \\
\overline{i_{1 c}}
\end{array}\right]-\left[\begin{array}{l}
\bar{i}_{2 a} \\
\overline{i_{2 b}} \\
\overline{i_{2 c}}
\end{array}\right]\right) \\
& \frac{d \bar{v}_{p v}}{d t}=-\frac{1}{C_{o}}\left[\begin{array}{l}
d_{a} \\
d_{b} \\
d_{c}
\end{array}\right]^{T} \cdot\left[\begin{array}{l}
\overline{i_{1}} \\
\overline{i_{1}} \\
\overline{\dot{i}_{1 c}}
\end{array}\right]+\frac{1}{C_{o}} \bar{i}_{p v}
\end{aligned}
$$

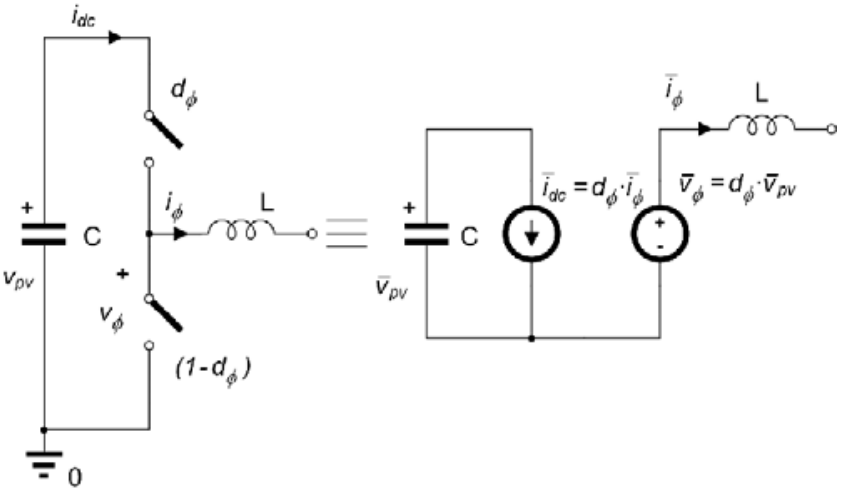

Fig. 2. Averaged equivalent circuit of an inverter leg. 


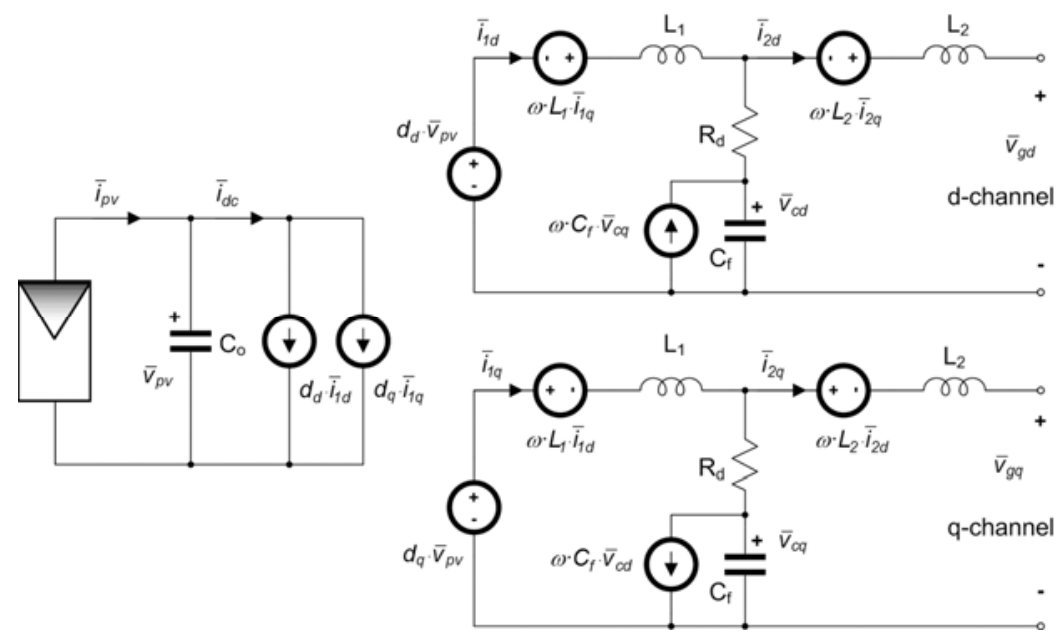

Fig. 4. Averaged equivalent circuit in a synchronous reference frame of a grid connected VSI photovoltaic inverter with LCL filter.

$$
\begin{gathered}
\mathbf{T}=\sqrt{\frac{2}{3}}\left[\begin{array}{ccc}
\cos (\omega t) & \cos \left(\omega t-\frac{2 \pi}{3}\right) & \cos \left(\omega t+\frac{2 \pi}{3}\right) \\
-\sin (\omega t) & -\sin \left(\omega t-\frac{2 \pi}{3}\right) & -\sin \left(\omega t+\frac{2 \pi}{3}\right) \\
\frac{1}{\sqrt{2}} & \frac{1}{\sqrt{2}} & \frac{1}{\sqrt{2}}
\end{array}\right] \\
{\left[\begin{array}{l}
\bar{x}_{d} \\
\bar{x}_{q} \\
\bar{x}_{o}
\end{array}\right]=\mathbf{T} \cdot\left[\begin{array}{l}
\bar{x}_{a} \\
\bar{x}_{b} \\
\bar{x}_{c}
\end{array}\right] \Leftrightarrow\left[\begin{array}{l}
\bar{x}_{a} \\
\bar{x}_{b} \\
\bar{x}_{c}
\end{array}\right]=\mathbf{T}^{-1} \cdot\left[\begin{array}{l}
\bar{x}_{d} \\
\bar{x}_{q} \\
\bar{x}_{o}
\end{array}\right]=\mathbf{T}^{T} \cdot\left[\begin{array}{l}
\bar{x}_{d} \\
\bar{x}_{q} \\
\bar{x}_{o}
\end{array}\right]}
\end{gathered}
$$

After transformation into the synchronous reference frame, the equations of the averaged model are expressed by (7)-(10). It's worth pointing out that there is no neutral wire connection, so that the $o$-channel has been omitted. Additional details may be found in the appendix.

Fig. 4 shows the equivalent averaged circuit in the synchronous reference $d q$ frame, following (7)-(10). Note the coupling terms between both the $d$ and $q$ channels. In the following sections a decoupling method is studied.

$$
\begin{aligned}
& \frac{d}{d t}\left[\begin{array}{c}
\bar{i}_{1 d} \\
\bar{i}_{1 q}
\end{array}\right]=\left[\begin{array}{cc}
\frac{-R_{d}}{L_{1}} & \omega \\
-\omega & \frac{-R_{d}}{L_{1}}
\end{array}\right] \cdot\left[\begin{array}{c}
\bar{i}_{1 d} \\
\bar{i}_{1 q}
\end{array}\right]+\frac{R_{d}}{L_{1}}\left[\begin{array}{c}
\bar{i}_{2 d} \\
\bar{i}_{2 q}
\end{array}\right] \\
& -\frac{1}{L_{1}}\left[\begin{array}{l}
\bar{v}_{c d} \\
\bar{v}_{c q}
\end{array}\right]+\frac{\bar{v}_{p v}}{L_{1}}\left[\begin{array}{l}
d_{d} \\
d_{q}
\end{array}\right] \\
& \frac{d}{d t}\left[\begin{array}{c}
\bar{i}_{2 d} \\
\overline{\dot{i}_{2 q}}
\end{array}\right]=\frac{R_{d}}{L_{2}}\left[\begin{array}{l}
\bar{i}_{1 d} \\
\overline{\dot{i}_{i q}}
\end{array}\right]+\left[\begin{array}{cc}
\frac{-R_{d}}{L_{2}} & \omega \\
-\omega & \frac{-R_{d}}{L_{2}}
\end{array}\right] \cdot\left[\begin{array}{l}
\overline{\dot{i}}_{2 d} \\
\overline{\dot{i}_{2 q}}
\end{array}\right] \\
& +\frac{1}{L_{2}}\left[\begin{array}{c}
\bar{v}_{c d} \\
\bar{v}_{c q}
\end{array}\right]-\frac{1}{L_{2}}\left[\begin{array}{c}
\bar{v}_{g d} \\
\bar{v}_{g q}
\end{array}\right]
\end{aligned}
$$

$$
\begin{aligned}
\frac{d}{d t}\left[\begin{array}{l}
\bar{v}_{c d} \\
\bar{v}_{c q}
\end{array}\right] & =\left[\begin{array}{cc}
0 & \omega \\
-\omega & 0
\end{array}\right] \cdot\left[\begin{array}{l}
\bar{v}_{c d} \\
\bar{v}_{c q}
\end{array}\right]+\frac{1}{C_{f}}\left(\left[\begin{array}{l}
\bar{i}_{d d} \\
\bar{i}_{1 q}
\end{array}\right]-\left[\begin{array}{l}
\bar{i}_{2 d} \\
\bar{i}_{2 q}
\end{array}\right]\right) \\
\frac{d \bar{v}_{p v}}{d t} & =-\frac{1}{C_{o}}\left[\begin{array}{l}
d_{d} \\
d_{q}
\end{array}\right]^{T} \cdot\left[\begin{array}{l}
\bar{i}_{1 d} \\
\bar{i}_{1 q}
\end{array}\right]+\frac{1}{C_{o}} \bar{i}_{p v}
\end{aligned}
$$

\section{B. Small signal modeling}

The small signal model of the three phase photovoltaic inverter may be found by perturbing the averaged variables around an operating point, as expressed by (11). In (11), $X$ and $\hat{x}$ denote the operating point value and the small signal term of the averaged $x$ variable, respectively.

$$
\bar{x}=X+\hat{x}
$$

The photovoltaic panels have been modeled by linearization of the curves $i_{p v}=i_{p v}\left(v_{p v}\right)$ around an operation point close to the maximum power point (MPP) of the panels. By neglecting the non linear term $\widehat{v}_{p v} \widehat{i}_{p v}$ and taking into account that $\widehat{p}_{p v}=0$ in an operating point close to the MPP, from the expression of the $\mathrm{PV}$ panels power it results

$$
\begin{aligned}
& \bar{p}_{p v}=P_{p v}+\hat{p}_{p v}=\bar{v}_{p v} \bar{i}_{p v} \\
& \quad=P_{p v}+V_{p v} \hat{i}_{p v}+\widehat{v}_{p v} I_{p v}+\widehat{v}_{p v} \hat{i}_{p v} \\
& \hat{p}_{p v}=V_{p v} \hat{i}_{p v}+\widehat{v}_{p v} I_{p v}=0 \\
& \hat{i}_{p v}=\left.\frac{-I_{p v}}{V_{p v}}\right|_{M P P} \cdot \widehat{v}_{p v}
\end{aligned}
$$

Generally, a PV source is composed by $n_{p}$ parallel branches of $n_{s}$ series connected panels per branch. In (13) the PV small signal response is expressed as a function of both the current and the voltage of one panel working around the MPP, $I_{p v 1}$ and $V_{p v 1}$, respectively.

$$
\begin{aligned}
& \hat{i}_{p v}=\frac{n_{p}}{n_{s}} \frac{-I_{p v 1}}{V_{p v 1}} \widehat{v}_{p v}=k_{p v} \widehat{v}_{p v} \\
& k_{p v}=-\left.\frac{n_{p}}{n_{s}} \frac{I_{p v 1}}{V_{p v 1}}\right|_{M P P}
\end{aligned}
$$




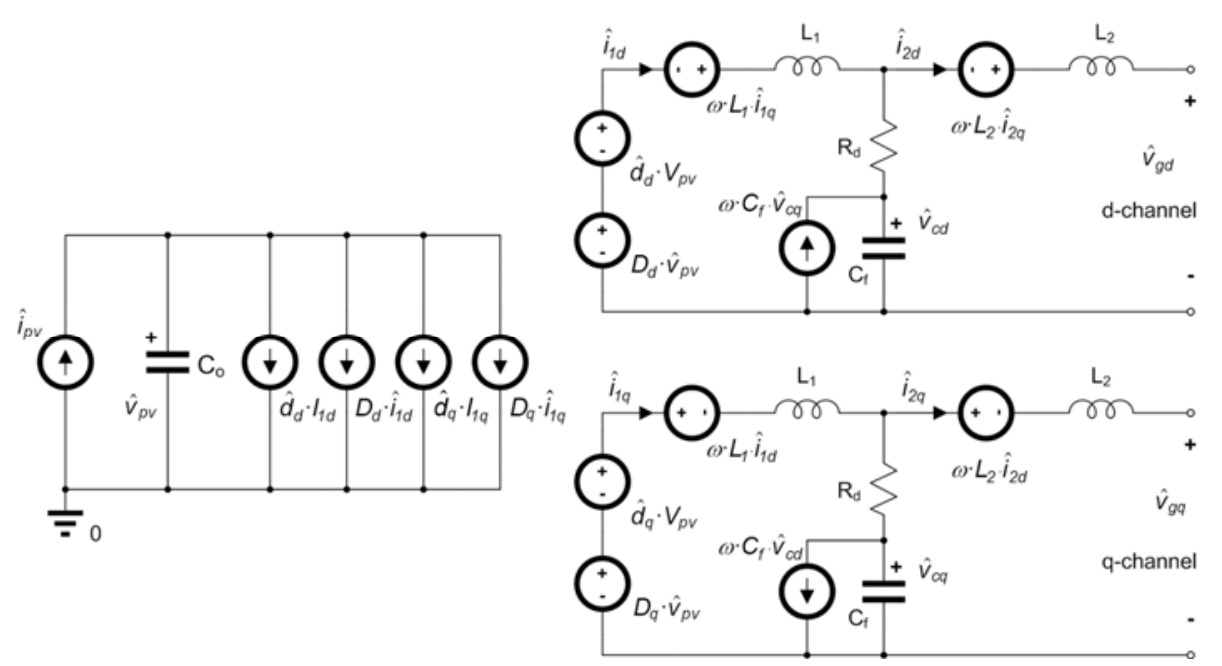

Fig. 5. Small-signal circuit in a synchronous reference frame of a grid connected VSI photovoltaic inverter with LCL filter

Following the described procedure, an accurate small signal model of the three phase photovoltaic inverter results, as it is expressed by (14). Fig. 5 shows the equivalent small-signal circuit of the photovoltaic inverter, which has been obtained starting from the state space equations in the chosen synchronous reference frame. The operating point must be calculated taking into account the control objectives. In this work, the current at the output of the inverter is desired to be in phase with the grid voltage, so that the reactive power demanded by the filter capacitors is supplied by the grid. Therefore, $I_{1 q}=0$. The rest of the operation point values are obtained by substituting (11) into (7)-(10), and solving for the static terms, that are summarized by Table I.

$$
\begin{gathered}
\frac{d}{d t} \mathbf{X}=\mathbf{A} \cdot \mathbf{X}+\mathbf{B} \cdot \mathbf{U} \\
\mathbf{Y}=\mathbf{C} \cdot \mathbf{X}+\mathbf{D} \cdot \mathbf{U}
\end{gathered}
$$

TABLE I

\section{EXPRESSIONS OF THE OPERATING POINT VALUES}

\begin{tabular}{ll}
\hline \hline Variable & \\
\hline$V_{g d}$ & $V_{g-R M S}$ (phase to phase) \\
$V_{g q}$ & 0 \\
$I_{1 d}$ & $I_{2 d}\left(1-\omega^{2} L_{2} C_{f}\right)-\omega I_{2 q} R_{d} C_{f}$ \\
$I_{1 q}$ & 0 \\
$I_{2 d}$ & $\frac{V_{p v} I_{p v}}{V_{g d}}$ \\
$I_{2 q}$ & $\frac{V_{g d}+\omega^{2} L_{2} C_{f} R_{d} I_{2 d}}{\omega^{2} L_{2} C_{f}-1+\left(\omega R_{d} C_{f}\right)^{2}}$ \\
$V_{c d}$ & $\frac{-I_{2 q}}{\omega C_{f}}$ \\
$V_{c q}$ & $\frac{I_{2 d}-I_{1 d}}{\omega C_{f}}$ \\
$D_{d}$ & $\frac{V_{g d}-\omega L_{2} I_{2 q}}{V_{p v}}$ \\
$D_{q}$ & $\frac{\omega\left(L_{1} I_{1 d}+L_{2} I_{2 d}\right)}{V_{p v}}$ \\
& \\
& \\
& \\
& \\
& \\
&
\end{tabular}

$$
\begin{aligned}
& \mathbf{X}=\mathbf{Y}=\left[\begin{array}{lllllll}
\hat{i}_{1 d} & \hat{i}_{1 q} & \hat{i}_{2 d} & \hat{i}_{2 q} & \hat{v}_{c d} & \hat{v}_{c q} & \hat{v}_{p v}
\end{array}\right]^{T} \\
& \mathbf{U}=\left[\begin{array}{llll}
\hat{d}_{d} & \hat{d}_{q} & \hat{v}_{g d} & \hat{v}_{g q}
\end{array}\right]^{T} \\
& \mathbf{A}=\left[\begin{array}{ccccccc}
\frac{-R_{d}}{L_{1}} & \omega & \frac{R_{d}}{L_{1}} & 0 & \frac{-1}{L_{1}} & 0 & \frac{D_{d}}{L_{1}} \\
-\omega & \frac{-R_{d}}{L_{1}} & 0 & \frac{R_{d}}{L_{1}} & 0 & \frac{-1}{L_{1}} & \frac{D_{q}}{L_{1}} \\
\frac{R_{d}}{L_{2}} & 0 & \frac{-R_{d}}{L_{2}} & \omega & \frac{1}{L_{2}} & 0 & 0 \\
0 & \frac{R_{d}}{L_{2}} & -\omega & \frac{-R_{d}}{L_{2}} & 0 & \frac{1}{L_{2}} & 0 \\
\frac{1}{C_{f}} & 0 & \frac{-1}{C_{f}} & 0 & 0 & \omega & 0 \\
0 & \frac{1}{C_{f}} & 0 & \frac{-1}{C_{f}} & -\omega & 0 & 0 \\
\frac{-D_{d}}{C_{o}} & \frac{-D_{q}}{C_{o}} & 0 & 0 & 0 & 0 & \frac{k_{p v}}{C_{o}}
\end{array}\right] \\
& \mathbf{B}=\left[\begin{array}{cccc}
\frac{V_{p v}}{L_{1}} & 0 & 0 & 0 \\
0 & \frac{V_{p v}}{L_{1}} & 0 & 0 \\
0 & 0 & \frac{-1}{L_{2}} & 0 \\
0 & 0 & 0 & \frac{-1}{L_{2}}
\end{array}\right] \quad \begin{array}{l}
\mathbf{C}=\mathbf{I} \\
\mathbf{D}=\mathbf{0}
\end{array} \\
& {\left[\begin{array}{cccc}
0 & 0 & 0 & 0 \\
0 & 0 & 0 & 0 \\
\frac{-I_{1 d}}{C_{o}} & \frac{-I_{1 q}}{C_{o}} & 0 & 0
\end{array}\right]}
\end{aligned}
$$




\section{Control of the PV inverter}

Fig. 6 shows the scheme of the chosen control structure in the synchronous reference frame or decomposition in $d q$ axes. A Synchronous Reference Frame PLL (SRF-PLL) [16] is used to synchronize the $d$-axis with the grid voltage vector. With this approach, the $d$ channel current loop allows the control of the active power that is supplied by the PV inverter, whereas the reactive power is controlled by the current in the $q$ channel. Generally, unity power factor at the output of the inverter is desired in order to minimize the inverter power losses. To achieve this objective, a null reference for the reactive current loop, $i_{\text {qref }}$, is chosen.

Stability of both the active and reactive current control loops can be studied by means of their respective current loop gains $T_{i d}(\mathrm{~s})$ and $T_{i q}(\mathrm{~s})$, following (15) and (16), respectively. The duty cycle to current transfer functions that appear in (15) and (16) are calculated from the state space equations (14). $R_{S}$ is the gain of the current transducers, $P I(s)$ are conventional PI regulators and $D(s)=e^{-s T d e l}$ allows to take into account both the digital and the PWM delays [26].

It's worth to point out a relevant issue relating to the position of the current sensors. In [24], it was shown that the robustness of the photovoltaic inverter improves if the current control loops are closed by sensing the phase currents in the inverter side instead of sensing in the grid side. Therefore, this solution has been chosen for the rest of the study and also for implementing the control stage in the experimental prototype.

$$
\begin{aligned}
& T_{i d}(s)=R_{s} \cdot P I_{i}(s) \cdot D(s) \cdot \frac{\hat{i}_{i d}(s)}{\hat{d}_{d}(s)} \\
& T_{i q}(s)=R_{s} \cdot P I_{i}(s) \cdot D(s) \cdot \frac{\hat{i}_{i q}(s)}{\widehat{d}_{q}(s)}
\end{aligned}
$$

After closing the inner current loops, an outer voltage loop maintains the panels' voltage close to a desired reference, which is calculated by the MPPT algorithm to extract the maximum power from the PV panels. Both the stability and the performance of the voltage loop may be studied by means of the voltage loop gain $T_{v}(\mathrm{~s})$, following (17). $\beta$ is the voltage sensor gain and $P I_{v}(s)$ is a conventional PI regulator.

$$
T_{v}(s)=\beta \cdot P I_{v}(s) \cdot \frac{\hat{i}_{1 d}(s)}{\hat{i}_{1 d r e f}(s)} \cdot \frac{\widehat{v}_{p v}(s)}{\hat{i}_{1 d}(s)}
$$

\section{Decoupling terms}

Fig. 4 shows the coupling terms between the $d$ and $q$ channels due to both the inductors currents and the voltage at the filtering capacitors in the complementary channel. Perfect decoupling is not possible with the described control structure, because the voltage across the ac capacitors and the current in the grid side are not sensed both for price and complexity reasons. However, an acceptable decoupling degree, that is valid from DC up to the medium frequency range, may be achieved by adding the decoupling terms $K_{d q}$ and $K_{q d}$ that appear in Fig. 6.

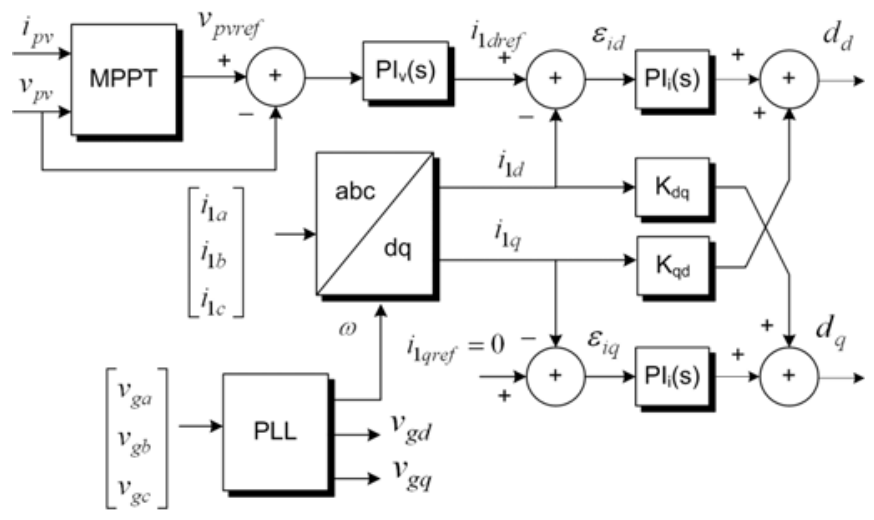

Fig. 6: Scheme of the digital control stage

The value of the decoupling factor $K_{q d}$ for the $d$-channel may be calculated by neglecting the $a c$ capacitors in the scheme shown by Fig. 5, so that $\widehat{i}_{1 d} \approx \widehat{i}_{2 d}$. With this approximation and assuming that $\widehat{v}_{p v}(s)=\widehat{v}_{g d}(s)=0$ it results in the $d$ channel

$$
\widehat{d}_{d}(s) \cdot V_{p v}+\omega \cdot\left(L_{1}+L_{2}\right) \cdot \hat{i}_{1 q}(s)=\left(L_{1}+L_{2}\right) s \cdot \hat{i}_{1 d}(s)
$$

Furthermore, being $\varepsilon_{i d}$ the current error signal in the $d$ channel, the control action in that channel with decoupling may be expressed as

$$
\widehat{d}_{d}(s)=P I_{i}(s) \hat{\varepsilon}_{i d}(s)+K_{q d} \hat{i}_{1 q}(s)
$$

From (18) and (19), the value of $K_{q d}$ that eliminates the coupling term may be calculated following (20). A similar procedure may be followed to calculate the value of the decoupling gain for the $q$ channel $K_{d q}$, as (21) expresses.

$$
\begin{aligned}
& K_{q d}=\frac{-\omega\left(L_{1}+L_{2}\right)}{V_{p v}} \\
& K_{d q}=\frac{\omega\left(L_{1}+L_{2}\right)}{V_{p v}}
\end{aligned}
$$

\section{Sensitivity Study of The Control Loops}

A study of the control loops sensitivity to variations of the power stage elements have been carried out by means of the proposed small-signal model. Table II summarizes the nominal values of the analyzed PV inverter and their range of variation. The study is based on a $100 \mathrm{~kW}$ PV inverter that is connected to the grid trough a 1:1 Dy transformer, so that the phase to phase voltage in the inverter side is $230 \mathrm{~V}$ for a $400 \mathrm{~V}$ grid. In Table II, $v_{g}, L_{g}$ and $L_{L K}$ denote the grid voltage, the grid inductance and the transformer leakage inductance, respectively, in all cases reduced to the inverter side. The transformer magnetizing inductances have been neglected. Note that no additional inductor has been used in the grid side because of the relatively large value of the transformer leakage inductance, so that the value of the grid side inductance for the small-signal model is $L_{2}=L_{L K}+L_{g}$. 
TABLE II

PARAMETERS OF THE THREE-PHASE PV INVERTER UNDER STUDY

\begin{tabular}{cl}
\hline Parameter & \multicolumn{1}{c}{ Nominal value or variation range } \\
\hline$V_{g-R M S}$ & $230 \mathrm{~V}$ phase to phase (delta connection) \\
$V_{p v}$ & {$[450 \mathrm{~V}, 800 \mathrm{~V}]$} \\
$P_{p v}$ & {$[1 \mathrm{~kW}, 100 \mathrm{~kW}]$} \\
$k_{p v}$ & {$[-0.1 \mathrm{~A} / \mathrm{V},-0.5 \mathrm{~A} / \mathrm{V}]$} \\
$C_{o}$ & $3 \mathrm{mF}$ \\
$L_{1}$ & $500 \mu \mathrm{H}$ \\
$L_{g}$ & {$[30 \mu \mathrm{H}, 120 \mu \mathrm{H}]$} \\
$L_{l k}$ & $100 \mu \mathrm{H}$ \\
$L_{2}$ & {$[130 \mu \mathrm{H}, 220 \mu \mathrm{H}]$} \\
$C_{f}$ & $99 \mu \mathrm{F}$ \\
$R_{d}$ & $0.3 \Omega$ \\
$f_{s}$ & $5 \mathrm{kHz}$ \\
$R_{s}$ & $0.003 \mathrm{~V} / \mathrm{A}$ \\
$\beta$ & $0.00125 \mathrm{~V} / \mathrm{V}$
\end{tabular}

TABLE III

SUMMARY OF EXPRESSIONS OF THE CHOSEN REGULATORS

\begin{tabular}{cc}
\hline \hline Controller & Expression in the continuous time domain \\
\hline$P I_{I}(s)$ & $K_{p i}+\frac{K_{i i}}{s}=0.8+\frac{0.02}{s}$ \\
$P I_{v}(s)$ & $K_{p v}+\frac{K_{i v}}{s}=8+\frac{0.02}{s}$
\end{tabular}

A set of damping resistors $R_{d}$ is placed in series with the filter capacitors. From the point of view of control loop stability the use of damping resistors can be avoided by means of some active damping control strategies reported by other authors [11]. Nevertheless, it is very convenient to use damping resistors from the point of view of robustness of the control loop to voltage harmonics in the grid, whose frequency could agree with the resonance frequency of the LCL filter, resulting in undamped oscillations, noise and even malfunction of the inverter. The total power loss in the damping resistors of the inverter under study is about $40 \mathrm{~W}$, i.e., $0.04 \%$ of full power.

Fig. 7 shows the curves of a SLK60P6L panel manufactured by Siliken S.A. By associating $n_{p}=27$ parallel branches of $n_{s}=20$ series connected panels per branch, a 120 $k W$ photovoltaic system results, with a range of variation of the overall transconductance that it is expressed in Table II, following (13).

The adopted MPPT Technique has been 'perturb\&observe'. Consequently, the value of the voltage reference, $v_{p v r e f}$, is continuously changing in steps whose size depends on the increment of the injected power that took place in the previous step. Nevertheless, the study around the operation point is realistic, because on one hand the refreshing frequency of the MPPT algorithm is much lower than that of the current and voltage loops, and on the other hand the steps in $v_{\text {pvref }}$ are small near the MPP. In fact, the operation point is quasistationary 'seen' by the voltage and current loops. The description of the MPPT algorithm is out of the scope of this paper. Details about this subject may be found in [19]-[23].

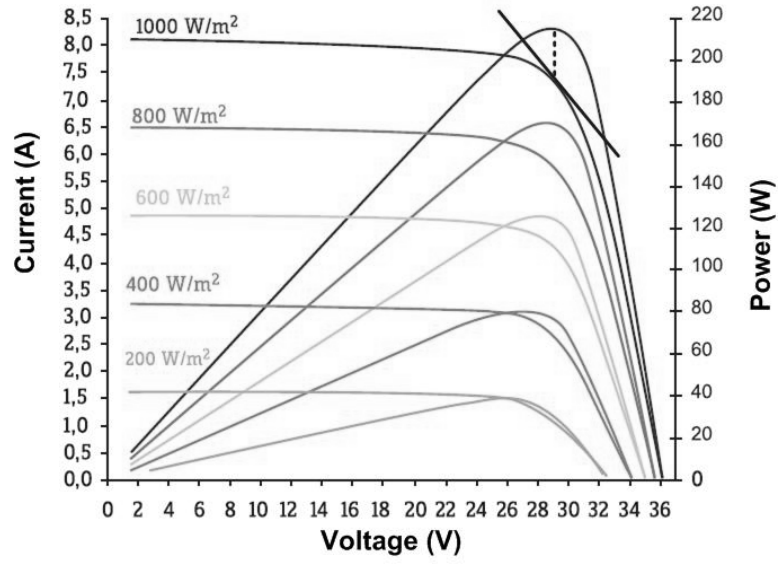

Fig. 7. Curves $i_{p v}\left(v_{p v}\right)$ of a photovoltaic panel SLK60P6L manufactured by Siliken S.A.

The sensitivity study has been performed taking into account a wide variation of $V_{p v}\left(V_{p v} \in[450 \mathrm{~V}, 750 \mathrm{~V}]\right)$, which is equivalent to a wide variation of the voltage reference. When $V_{p v}$ is outside the described interval the inverter doesn't inject power to the grid.

Table III shows the expression of the chosen regulators for both the inner current loops and the outer voltage loop, $P I_{i}(\mathrm{~s})$ and $P I_{v}(s)$, respectively. A delay $T_{d e l}=200 \mu$ s, equivalent to a switching period, has been considered and introduced in the analysis by means of a second order Padé approximation [26], as expressed by (22).

$$
e^{-T_{\text {del }} \cdot s} \approx \frac{1-0.5 \cdot T_{d e l} \cdot s+0.083 \cdot\left(T_{d e l} \cdot s\right)^{2}}{1+0.5 \cdot T_{d e l} \cdot s+0.083 \cdot\left(T_{d e l} \cdot s\right)^{2}}
$$

The sensitivity study was performed by means of a 4dimensional MATLAB ${ }^{\circledR}$ LTI array [27] with the small-signal model of (14.1) to (14.4), including the delays and the control structure. The dimensions of the array agree with the 4 parameters that undergo wider variations or uncertainty: the injected power, $P_{p v}$, the DC voltage at the $\mathrm{PV}$ panels arrangement, $V_{p v}$, the grid plus leakage side inductance seen from the inverter side, $L_{2}$, and the PV panels arrangement transconductance, $k_{p v}$. The 4 parameters are operation point values that define the dynamics of the small-signal model.

Fig. 8 shows the theoretical Bode plots of $T_{i d}(j \omega)$ and $T_{i q}(j \omega)$ with different combinations of $V_{p v}$ and $P_{p v}$, being $k_{p v}=0.3 \mathrm{~A} / \mathrm{V}$ and $L_{2}=180 \mu \mathrm{H}$. A low frequency resonance with a frequency ranging between $30 \mathrm{~Hz}$ and $60 \mathrm{~Hz}$ is observed. If $V_{p v}$ increases, the resonance frequency decreases and its damping factor increases. The effect of $P_{p v}$ variations on the current loop is negligible.

In both the $d$ and $q$ current loops, the crossover frequency ranges from $250 \mathrm{~Hz}$ to $450 \mathrm{~Hz}$, in all cases with proper stability margins (phase margin $P M>50^{\circ}$ and gain margin $G M>10 \mathrm{~dB}$ ). 
Fig. 9 shows the analytical Bode plots of $T_{i d}(j \omega)$ and $T_{i q}(j \omega)$ with variations of $L_{2}$ and $k_{p v}$, being $V_{p v}=600 \mathrm{~V}$ and $P_{p v}=100$ $k W$. On one hand it is observed that the high frequency resonance due to the LCL grid filter increases its peak for high values of $\mathrm{L}_{2}$. On the other hand, if $k_{p v}$ increases, the low frequency resonance of the current loop gain becomes more damped.

Fig. 10 shows the theoretical Bode plots of $T_{v}(j \omega)$ with different combinations of $V_{p v}$ and $P_{p v}$, being $k_{p v}=0.3 \mathrm{~A} / \mathrm{V}$ and $L_{2}=180 \mu \mathrm{H}$. If $V_{p v}$ increases, the crossover frequency of the voltage loop decreases. If $P_{p v}$ increases, the crossover frequency slightly increases. It is observed that the voltage loop crossover frequency ranges from $50 \mathrm{~Hz}$ to $100 \mathrm{~Hz}$, with proper stability margins (phase margin $P M>50^{\circ}$ and gain margin $G M>10 \mathrm{~dB}$ ) in all cases.

Fig. 11 shows the analytical Bode plots of $T_{v}(j \omega)$ with variations of $L_{2}$ and $k_{p v}$, being $V_{p v}=600 \mathrm{~V}$ and $P_{p v}=100 \mathrm{~kW}$. It is observed that for small values of $k_{p v}$, the phase of $T_{v}(j \omega)$ is very negative at low frequency, so that it should be avoided to choose a very low crossover frequency of the voltage loop.

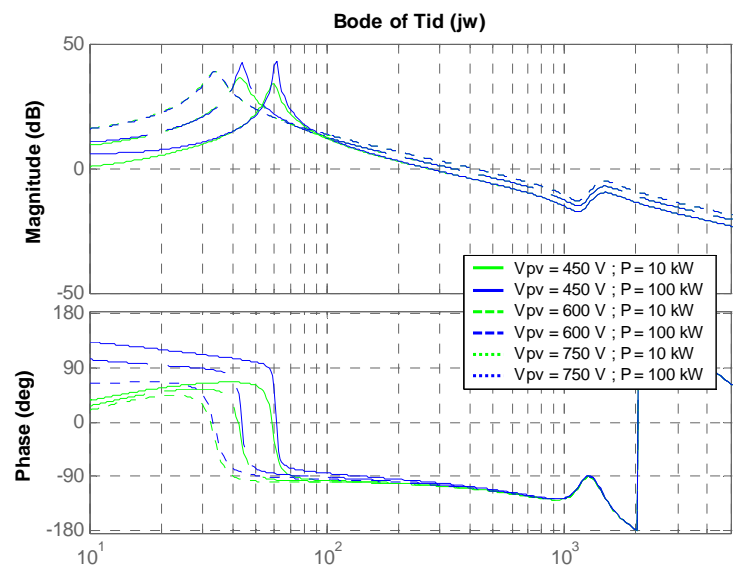

(a)

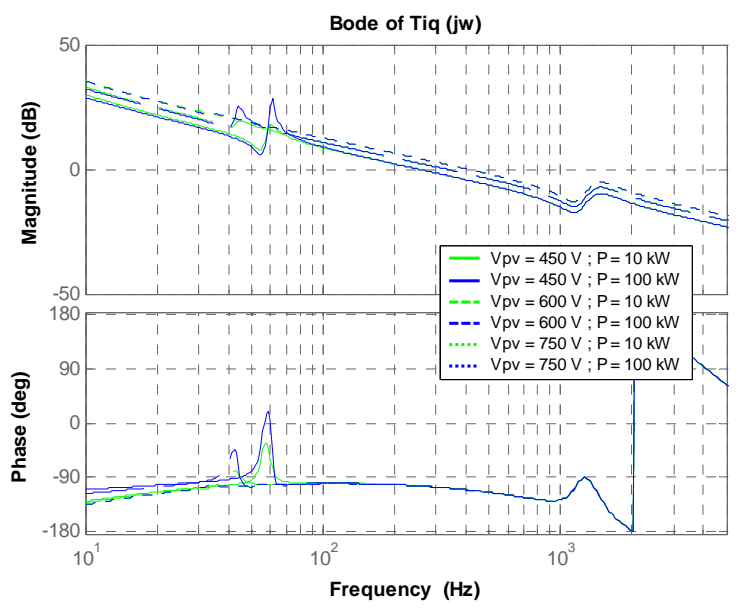

(b)

Fig. 8. Analytical Bode plots of the current loop gain with variations of $V_{p v}$ and $P_{p v}\left(k_{p v}=0.3 \mathrm{~A} / \mathrm{V}, L_{2}=180 \mu \mathrm{H}\right)$. (a) $d$ channel, $T_{i d}(\mathrm{~s})$. (b) $q$ channel, $T_{i q}(\mathrm{~s})$.

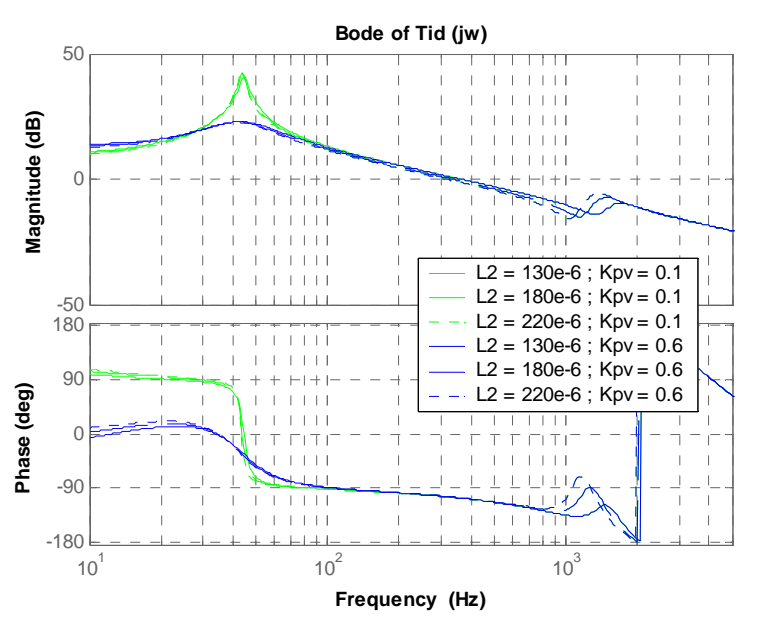

(a)

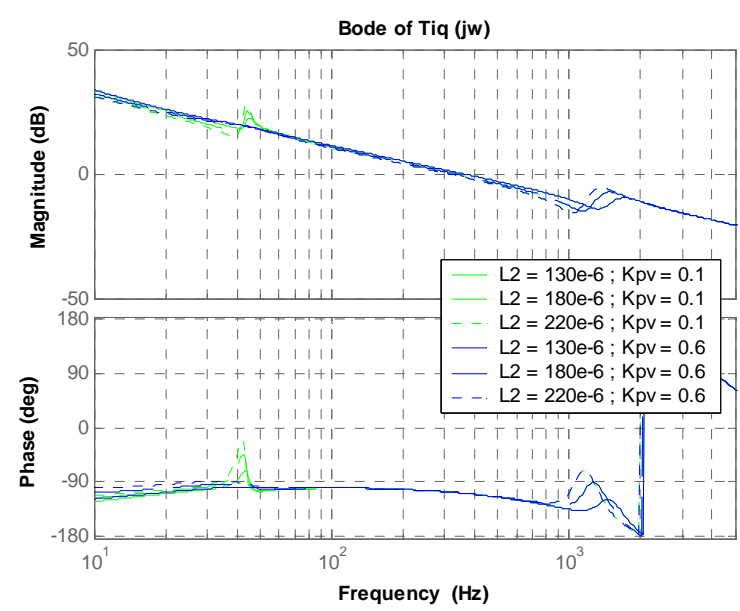

(b)

Fig. 9. Analytical Bode plots of the current loop gain with variations of $L_{2}$ and $k_{p v}$ and $\left(V_{p v}=600 \mathrm{~V}, P_{p v}=100 \mathrm{~kW}\right)$. (a) $d$ channel, $T_{i d}(\mathrm{~s})$. (b) $q$ channel, $T_{i q}(\mathrm{~s})$.

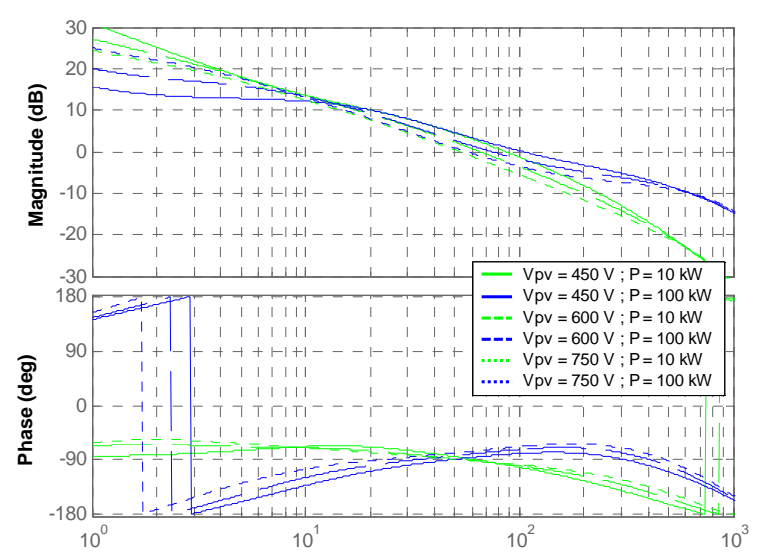

Fig. 10. Analytical Bode plots of the voltage loop gain with variations of $V_{p v}$ and $P_{p v}\left(k_{p v}=0.3 \mathrm{~A} / \mathrm{V}, L_{2}=180 \mu \mathrm{H}\right)$. 


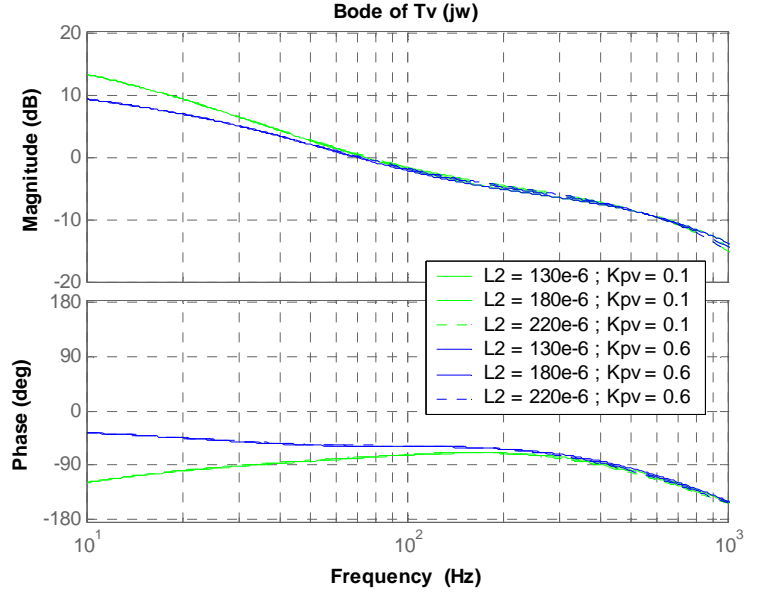

Fig. 11. Analytical Bode plots of the voltage loop gain with variations of $L_{2}$ and $k_{p v}$ and $\left(V_{p v}=600 \mathrm{~V}, P_{p v}=100 \mathrm{~kW}\right)$.

\section{EXPERIMENTAL RESULTS}

The $100 \mathrm{~kW}$ inverter under study is commercialized by the company Siliken Electronics. The values of the power stage parameters were described in Table II. The control stage has been implemented on a TMS320F2812 digital signal processor with a sampling frequency of $2 \cdot f \mathrm{~s}=10 \mathrm{kHz}$.

A test unit of this inverter has been installed in a $4.3 \mathrm{MW}$ photovoltaic farm in Casas Ibáñez (Albacete, Spain). An antiislanding algorithm has been implemented to detect grid faults, but its description is beyond the scope of this paper.

The grid synchronization method is the well known Synchronous Reference Frame PLL (SRF-PLL) [16], which is a very common technique to solve the problem of inverters grid synchronization. In these conditions the commercial inverter has been working without major failures in the PV park for more than one year.

In [24] it was reported that the $T H D_{i}$ was lower than $3 \%$ for all phase currents, whereas the fulfillment of the limits established by the IEC 61000-3-4 norm was shown. In this paper the experimental results are focused on the validation of the proposed small-signal model.

Fig. 12 shows the experimental setup for obtaining the Bode plots of the current loop gain in the d-axis, $T_{i d}(s)$, by means of a frequency response analyzer (FRA) NF Corporation FRA 5097. $\mathrm{G}_{\mathrm{i}}(\mathrm{z})$ are the current regulators in a digital implementation and the decoupling paths have been omitted for simplicity. The oscillator output of the analyzer is added through an A/D converter to the current feedback signal in the d-axis. The resulting signal and the feedback signal are driven through PWM ports of the DSP to measuring channels 2 and 1 of the FRA, respectively. The transfer function $T_{i d}(s)$ results from the transfer function between both channels of the FRA: $T_{i d}(s)=\mathrm{CH} 1(\mathrm{~s}) / \mathrm{CH} 2(\mathrm{~s})$. Note that the tracking band-pass filter of the FRA filters out the high frequency contents of the PWM signals, only detecting the frequency component of the signal of interest which agrees with the oscillator frequency, which has been swept from $100 \mathrm{~Hz}$ to $3 \mathrm{kHz}$. A similar setup has been adopted for measuring the rest of Bode plots.
When the inverter is connected to the PV panels the operation point is variable due to the variable $v_{\text {pvref }}$ coming from the MPPT algorithm, so that the dynamic measurements cannot be performed working directly form the PV panels. Therefore, we have connected the inverter to a programmable DC power supply (4 Regatron TCP.32.1000.400.S modules in parallel) configured as a current source in order to have an operation point of $V_{p v}$ defined by a constant value of $v_{p v r e f}$ defined in the DSP software by the user, but not by the MPPT algorithm, which has been disabled for the measurements. Different I-V curves have been programmed for the DC power supply in order to emulate the PV panels.

In order to validate the proposed model, the Bode plots of the most important transfer functions at various operation points have been obtained and compared to the theoretical ones. From the measurements we have estimated a grid inductance of $L_{g}=80 \mu \mathrm{H}$, so that in all the theoretical Bode plots the value chosen for $\mathrm{L}_{2}$ has been $180 \mu \mathrm{H}$.

Fig. 13 shows the experimental and analytical Bode plots of $T_{\text {id }}(\mathrm{s})$ at $V_{p v}=450 \mathrm{~V}$ and $750 \mathrm{~V}$, at a power of $P_{p v}=50 \mathrm{~kW}$ in both cases. Fig. 14 shows the Bode plots of $T_{i q}(\mathrm{~s})$ at the same operation point of Fig. 13. Fig. 15 (a) shows the experimental and analytical Bode plots of the closed loop current response in the d-channel $i_{d}(s) / i_{\text {dref }}(s)$, and the cross-coupling current response $i_{q}(s) / i_{\text {dref }}(s)$ with and without decoupling. Fig. 15 (b) shows the experimental and analytical Bode plots of the closed loop current response in the q-channel $i_{q}(s) / i_{q r e f}(s)$, and the cross-coupling current response $i_{d}(s) / i_{\text {qref }}(s)$ with and without decoupling. The operation point of fig. 15 is: $V_{p v}=600$ $V$ and $P_{p v}=50 \mathrm{~kW}$. The decoupling achieves a cross-coupling reduction of more than $20 \mathrm{~dB}$ in a wide low frequency range.

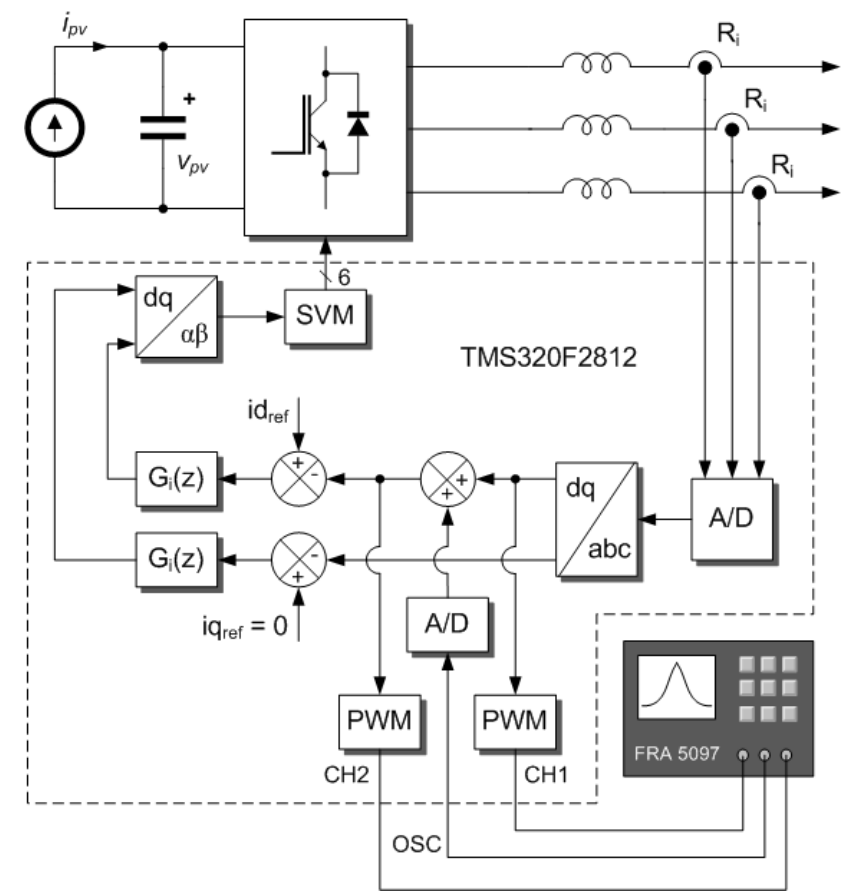

Fig. 12. Experimental setup for obtaining the Bode plots of the current loop gain in the d-axis, $T_{i d}(s)$, using a frequency response analyzer. 

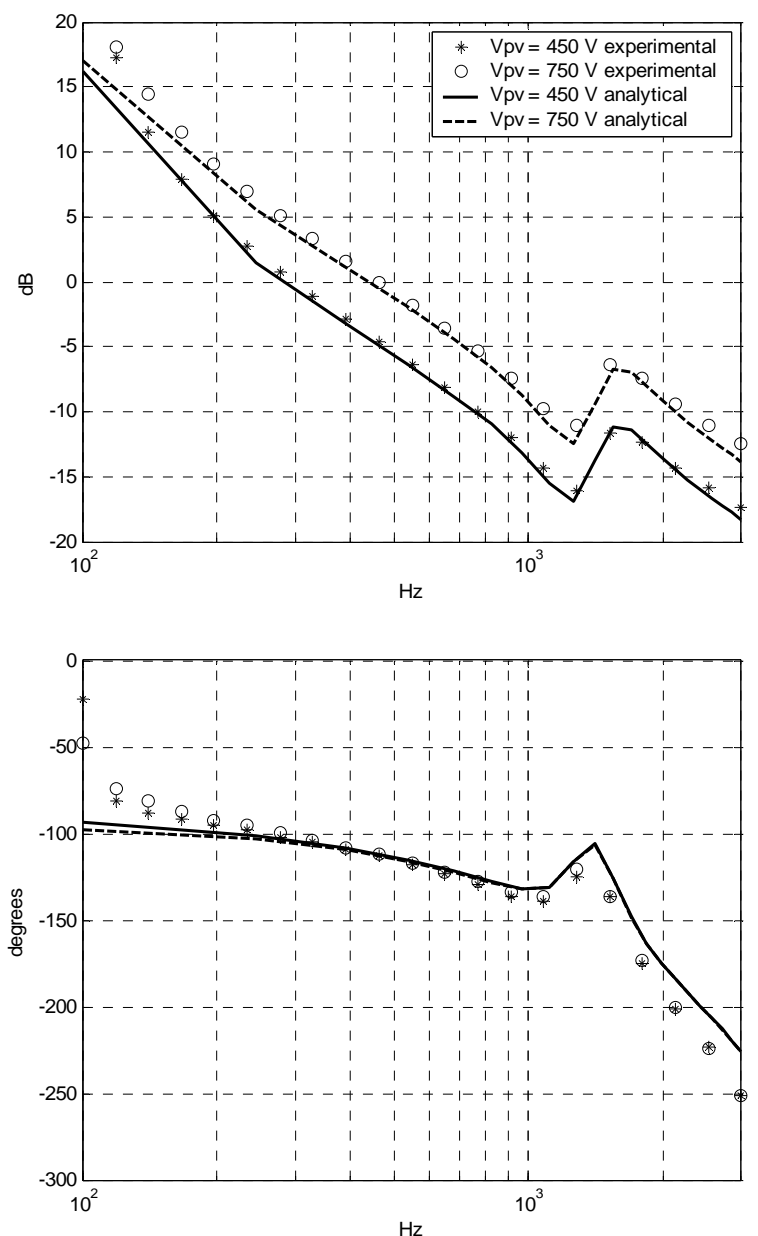

Fig. 13. Experimental and analytical Bode plots of $T_{i d}(S)$ at $V_{p v}=450 \mathrm{~V}$ and $750 \mathrm{~V}$, at a power of $P_{p v}=50 \mathrm{~kW}$.

Fig. 16 shows the experimental and analytical Bode plots of the voltage loop gain $T_{v}(\mathrm{~s})$ at $V_{p v}=450 \mathrm{~V}$ and $750 \mathrm{~V}$, at a power of $P_{p v}=45 \mathrm{~kW}$ and $75 \mathrm{~kW}$, respectively.

It is observed that the experimental Bode plots agree with the theoretical ones in an acceptable degree.

\section{CONCLUSION}

In this paper, two contributions to the field of PV generation have been presented. On one hand, an accurate small signal model of high power grid connected PV inverters with LCL filter has been derived. The model takes into account both the inverter operating point and the PV panels features. On the other hand, by using the proposed model a sensitivity study of the dynamics of a $100 \mathrm{~kW}$ inverter has been carried out, showing the influence of individual parameters on both the current and the voltage loop. Measurements by means of a frequency response analyzer have been carried out in order to validate the proposed model. The results may be especially useful to perform a proper tuning of both the voltage and current controllers when a wide dispersion of the system parameters is expected.
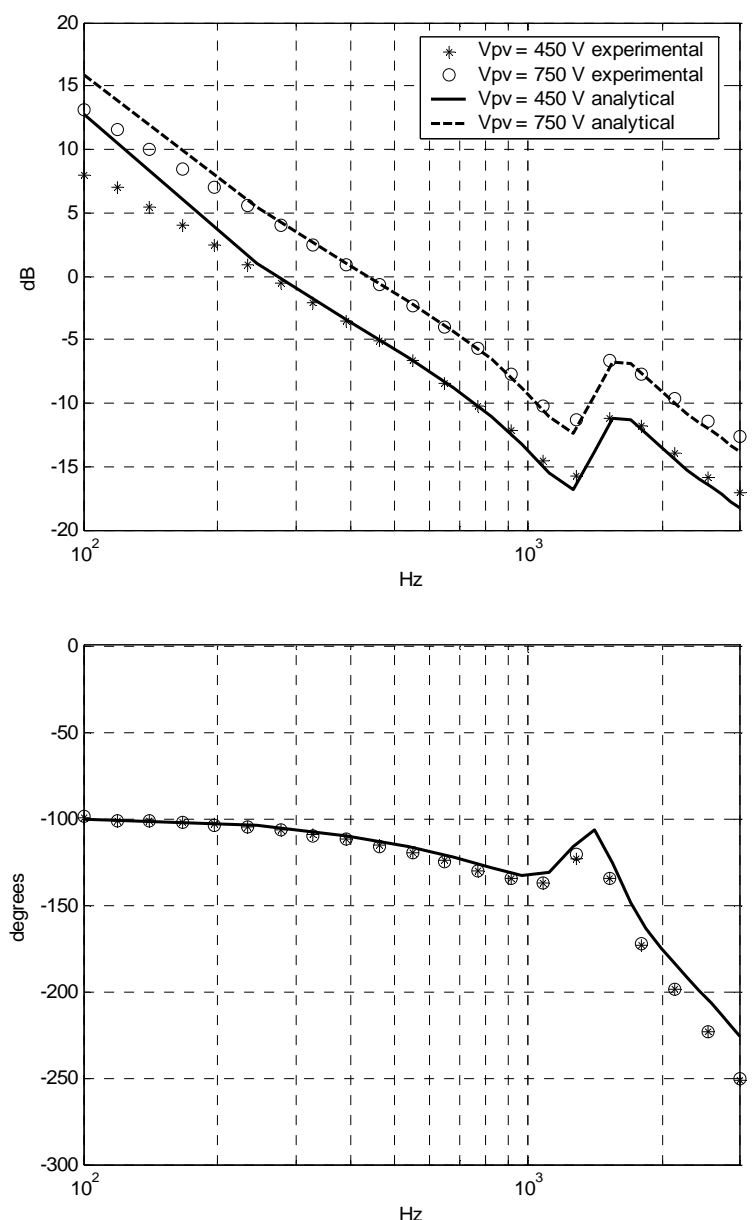

Fig. 14. Experimental and analytical Bode plots of $T_{i q}(\mathrm{~s})$ at $V_{p v}=450 \mathrm{~V}$ and 750 $\mathrm{V}$, at a power of $P_{p v}=50 \mathrm{~kW}$.

\section{APPENDIX}

The averaged model of the inverter in a synchronous reference frame may be found by applying (5) and (6) to (1)(4). After solving for the derivative terms and left multiplying by $\mathrm{T}$, the following set of equations results

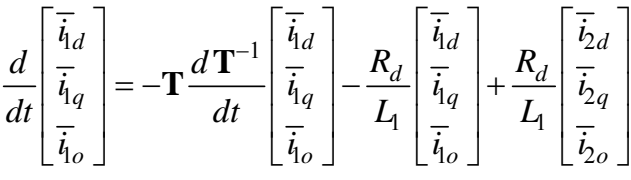

$$
\begin{aligned}
& -\frac{1}{L_{1}}\left[\begin{array}{l}
\bar{v}_{c d} \\
\bar{v}_{c q} \\
\bar{v}_{c o}
\end{array}\right]+\frac{\bar{v}_{p v}}{L_{1}}\left[\begin{array}{l}
d_{d} \\
d_{q} \\
d_{o}
\end{array}\right]-\frac{\sqrt{3} \bar{v}_{N^{\prime}}}{L_{1}}\left[\begin{array}{l}
0 \\
0 \\
1
\end{array}\right] \\
& \frac{d}{d t}\left[\begin{array}{l}
{\overline{i_{2 d}}}_{\bar{i}_{2 q}} \\
\overline{\dot{i}_{2 o}}
\end{array}\right]=-\mathbf{T} \frac{d \mathbf{T}^{-1}}{d t}\left[\begin{array}{l}
{\overline{i_{2}}}_{2 d} \\
\bar{i}_{2 q} \\
\overline{\dot{i}_{2 o}}
\end{array}\right]+\frac{R_{d}}{L_{2}}\left[\begin{array}{l}
\bar{i}_{1 d} \\
\overline{\dot{i}_{1 q}} \\
\overline{\dot{i}_{1 o}}
\end{array}\right]-\frac{R_{d}}{L_{2}}\left[\begin{array}{l}
\bar{i}_{2 d} \\
\bar{i}_{2 q} \\
\overline{\dot{i}_{2 o}}
\end{array}\right] \\
& +\frac{1}{L_{2}}\left[\begin{array}{c}
\bar{v}_{c d} \\
\bar{v}_{c q} \\
\bar{v}_{c o}
\end{array}\right]-\frac{1}{L_{2}}\left[\begin{array}{c}
\bar{v}_{g d} \\
\bar{v}_{g q} \\
\bar{v}_{g o}
\end{array}\right]-\frac{\bar{v}_{N}-\bar{v}_{N^{\prime}}}{L_{2}}\left[\begin{array}{l}
0 \\
0 \\
1
\end{array}\right]
\end{aligned}
$$




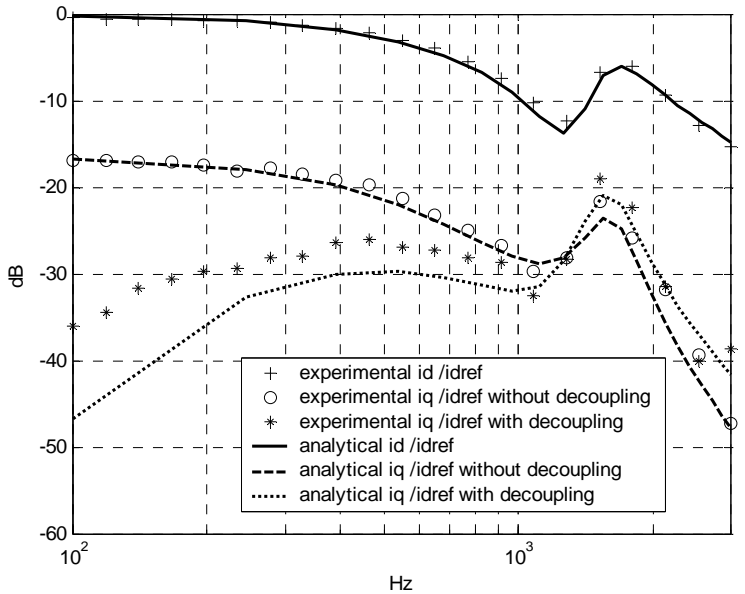

(a)

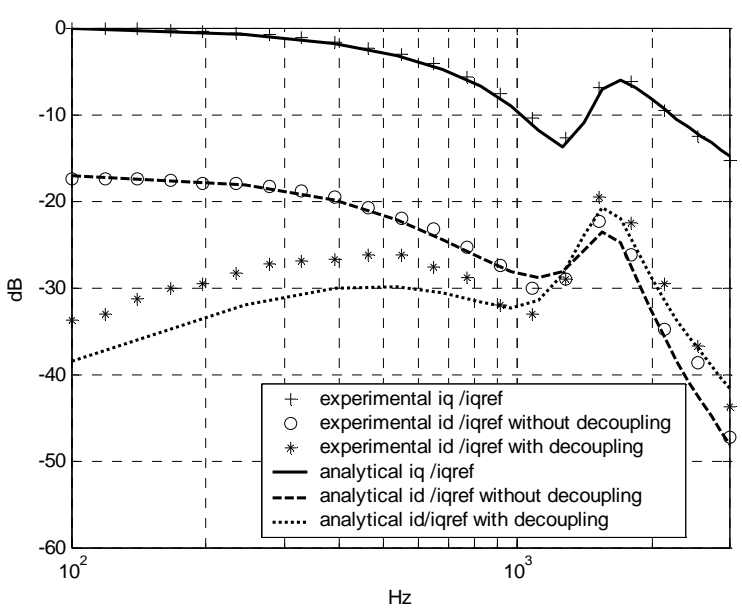

(b)

Fig. 15 Experimental and analytical Bode plots of the closed loop current response. (a) $i_{d}(s) / i_{\text {dref }}(s)$ and $i_{q}(s) / i_{\text {dref }}(s)$. (b) $i_{q}(s) / i_{\text {qref }}(s)$ and $i_{d}(s) / i_{\text {qref }}(s)$. The operation point is: $V_{p v}=600 \mathrm{~V}$ and $P_{p v}=50 \mathrm{~kW}$.

$$
\begin{aligned}
& \frac{d}{d t}\left[\begin{array}{l}
\bar{v}_{c d} \\
\bar{v}_{c q} \\
\bar{v}_{c o}
\end{array}\right]=-\mathbf{T} \frac{d \mathbf{T}^{-1}}{d t}\left[\begin{array}{l}
\bar{v}_{c d} \\
\bar{v}_{c q} \\
\bar{v}_{c o}
\end{array}\right]+\frac{1}{C_{f}}\left(\left[\begin{array}{c}
\bar{i}_{d d} \\
\bar{i}_{q q} \\
\bar{i}_{l o}
\end{array}\right]-\left[\begin{array}{c}
\bar{i}_{2 d} \\
\bar{i}_{2 q} \\
\bar{i}_{2 o}
\end{array}\right]\right) \\
& \frac{d \bar{v}_{p v}}{d t}=-\frac{1}{C_{o}}\left(\mathbf{T}^{-1}\left[\begin{array}{l}
d_{d} \\
d_{q} \\
d_{o}
\end{array}\right]\right)^{T} \cdot \mathbf{T}^{-1}\left[\begin{array}{l}
\bar{i}_{1 d} \\
\bar{i}_{1 q} \\
\overline{i_{o}}
\end{array}\right]+\frac{1}{C_{o}} \bar{i}_{p v} \\
& =-\frac{1}{C_{o}}\left[\begin{array}{l}
d_{d} \\
d_{q} \\
d_{o}
\end{array}\right]^{T} \cdot\left[\begin{array}{l}
\bar{i}_{1 d} \\
\bar{i}_{1 q} \\
\overline{i_{1}}
\end{array}\right]+\frac{1}{C_{o}} \bar{i}_{p v}
\end{aligned}
$$
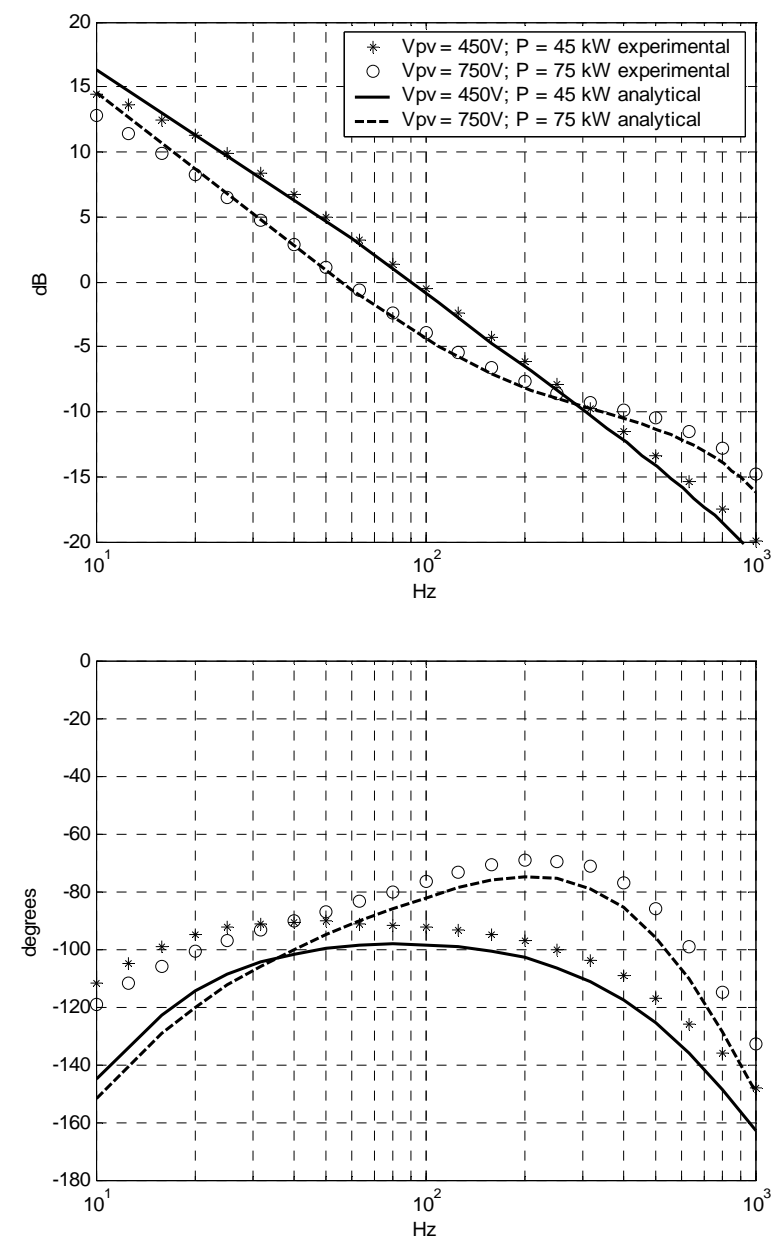

Fig. 16. Experimental and analytical Bode plots of the voltage loop gain $T_{v}(\mathrm{~s})$ at $V_{p v}=450 \mathrm{~V}$ and $750 \mathrm{~V}$, at a power of $P_{p v}=45 \mathrm{~kW}$ and $75 \mathrm{~kW}$, respectively.

Taking into account that

$$
\mathbf{T} \frac{d \mathbf{T}^{-1}}{d t}=\left[\begin{array}{ccc}
0 & -\omega & 0 \\
\omega & 0 & 0 \\
0 & 0 & 0
\end{array}\right]
$$

The equations of the averaged model in the synchronous reference frame are

$$
\begin{gathered}
\frac{d}{d t}\left[\begin{array}{l}
\bar{i}_{1 d} \\
\bar{i}_{1 q} \\
\bar{i}_{1 o}
\end{array}\right]=\left[\begin{array}{ccc}
\frac{-R_{d}}{L_{1}} & \omega & 0 \\
-\omega & \frac{-R_{d}}{L_{1}} & 0 \\
0 & 0 & \frac{-R_{d}}{L_{1}}
\end{array}\right]\left[\begin{array}{l}
\bar{i}_{1 d} \\
\bar{i}_{1 q} \\
\bar{i}_{l o}
\end{array}\right]+\frac{R_{d}}{L_{1}}\left[\begin{array}{l}
\bar{i}_{2 d} \\
\bar{i}_{2 q} \\
\bar{i}_{2 o}
\end{array}\right] \\
-\frac{1}{L_{1}}\left[\begin{array}{c}
\bar{v}_{c d} \\
\bar{v}_{c q} \\
\bar{v}_{c o}
\end{array}\right]+\frac{\bar{v}_{p v}}{L_{1}}\left[\begin{array}{c}
d_{d} \\
d_{q} \\
d_{o}
\end{array}\right]-\frac{\sqrt{3} \bar{v}_{N^{\prime}}}{L_{1}}\left[\begin{array}{l}
0 \\
0 \\
1
\end{array}\right]
\end{gathered}
$$




$$
\begin{aligned}
& \frac{d}{d t}\left[\begin{array}{c}
\bar{i}_{2 d} \\
\bar{i}_{2 q} \\
\bar{i}_{2 o}
\end{array}\right]=\left[\begin{array}{ccc}
\frac{-R_{d}}{L_{2}} & \omega & 0 \\
-\omega & \frac{-R_{d}}{L_{2}} & 0 \\
0 & 0 & \frac{-R_{d}}{L_{2}}
\end{array}\right]\left[\begin{array}{l}
\bar{i}_{i_{d}} \\
\bar{i}_{2 q} \\
\bar{i}_{2 o}
\end{array}\right]+\frac{R_{d}}{L_{2}}\left[\begin{array}{c}
\bar{i}_{i_{d}} \\
\bar{i}_{1 q} \\
\bar{i}_{1 o}
\end{array}\right] \\
& +\frac{1}{L_{2}}\left[\begin{array}{c}
\bar{v}_{c d} \\
\bar{v}_{c q} \\
\bar{v}_{c o}
\end{array}\right]-\frac{1}{L_{2}}\left[\begin{array}{c}
\bar{v}_{g d} \\
\bar{v}_{g q} \\
\bar{v}_{g o}
\end{array}\right]-\frac{\bar{v}_{N}-\bar{v}_{N^{\prime}}}{L_{2}}\left[\begin{array}{l}
0 \\
0 \\
1
\end{array}\right] \\
& \frac{d}{d t}\left[\begin{array}{l}
\bar{v}_{c d} \\
\bar{v}_{c q} \\
\bar{v}_{c o}
\end{array}\right]=\left[\begin{array}{ccc}
0 & \omega & 0 \\
-\omega & 0 & 0 \\
0 & 0 & 0
\end{array}\right]\left[\begin{array}{l}
\bar{v}_{c d} \\
\bar{v}_{c q} \\
\bar{v}_{c o}
\end{array}\right]+\frac{1}{C_{f}}\left(\left[\begin{array}{l}
\bar{i}_{l_{d}} \\
\bar{i}_{1 q} \\
\bar{i}_{l o}
\end{array}\right]-\left[\begin{array}{c}
\bar{i}_{\bar{i}_{d}} \\
\bar{i}_{i} \\
\bar{i}_{2 o}
\end{array}\right]\right) \\
& \frac{d \bar{v}_{p v}}{d t}=-\frac{1}{C_{o}}\left[\begin{array}{l}
d_{d} \\
d_{q} \\
d_{o}
\end{array}\right]^{T} \cdot\left[\begin{array}{l}
\bar{i}_{1 d} \\
\bar{i}_{1 q} \\
\overline{i_{1 o}}
\end{array}\right]+\frac{1}{C_{o}} \bar{i}_{p v}
\end{aligned}
$$

The neutral wire is not connected, so that the sum of the ac currents in the three phases is null. Therefore, all the currents in the $o$-channel are zero, so that this channel may be omitted.

\section{REFERENCES}

[1] "Electromagnetic compatibility (EMC)-Part 3: Limits for harmonic current emissions (equipment input current $>16 \mathrm{~A}$ per phase)", IEC 61000-3-4 Document, 1998.

[2] IEEE Standard for Interconnecting Distributed Resources with ElectricPower Systems, IEEE15471, 2005.

[3] Liserre, M., Blaabjerg, F., Hansen, S. "Design and control of an LCLfilter based Three-phase Active Rectifier", in IEEE Transactions on Industry Applications, vol.41, pp.1281-1291, sep-oct.2005.

[4] Serpa, L.A., Ponnaluri, S., Barbosa, P.M., Kolar, J.W. "A modified Direct Power Control Strategy Allowing the Connection of Three-phase Inverters to the Grid Trough LCL filters", in IEEE Transactions on Industry Applications, vol. 43, pp. 1388-1400, sept.-oct. 2007.

[5] Bolsens, B., De Brabandere, K., Vand den Keybus, J., Driesen, J., Belmans, R., "Model based generation of low distortion currents in gridcoupled PWM inverters using an LCL output filter", in IEEE Transactions on Power Electronics, vol..21, pp.1032-1040, july 2006.

[6] Twining, E., Holmes, D.G., "Grid current regulation of a three-phase voltage source inverter with an LCL input filter", in IEEE Transactions on Power Electronics, vol..18, pp.888-895, may 2003.

[7] Liserre, M., Blaabjerg, F., Teodorescu, R., "Grid impedance estimation via excitation of LCL filter resonance", in IEEE Transactions on Industry Applications, vol. 43, pp. 1041-1047, sept.-oct. 2007.

[8] Alepuz, S., Busquets-Monge, S., Bordonau, J., Gago, J., Gonzalez, D., Balcells, J, "Interfacing Renewable Energy Sourcer to the Utility Grid Using a Three-Level Inverter", in IEEE Transactions on Industrial Electronics, vol.53, pp. 1504-1511, oct. 2006.

[9] Guoqiao, S., Dehong Xu, Danji Xi, Xiaoming, Y., An improved control strategy for grid connected voltage source inverters with a LCL filter, Proceedings of the Applied Power Electronics and Exposition, 2006, APEC'06, pp. 1-7.

[10] Wai, R.J., Wang, W.H., Lin, C.Y., "High performance stand-alone photovoltaic generation system", in IEEE Transactions on Industria Electronics, vol. 55, pp.240-250, jan. 2008.

[11] Liserre, M., Dell'Aquila, A., Blaabjerg, F., "Genetic algorithm-based of the active damping for an LCL filter three-phase active rectifier", in IEEE Transactions on Power Electronics, vol.19, pp.76-86, jan. 2004.

[12] Liserre, M, Teodorescu, R., Blaabjerg, F., "Stability of photovoltaic and wind turbine grid connected inverters for a large set of grid impedance values", in IEEE Transactions on Power Electronics, vol.21, pp.263272, jan.2006.

[13] Malinowski et al, "A simple voltage sensorless active damping scheme for three phase PWM converters with LCL filter", in IEEE Transactions on Industrial Electronics, vol.55, pp.1876-1880, April 2008.

[14] Wu, E., Lehn, P.W., "Digital Current Control of a Voltage Source Converter With Active Damping of LCL Resonance", in IEEE Transactions on Power Electronics, vol. 21, pp.1364-1373, sept. 2006.

[15] Se-Kyo, C., "A phase tracking system for three phase utility interface inverters", in IEEE Transactions on Power Electronics, vol. 15, pp. 431438, may 2000 .

[16] Blaabjerg, F., Teodorescu, R., Liserre, M, Timbus, A.V., "Overview of control and grid synchronization for distributed power generation systems", in IEEE Transactions on Industrial Electronics, vol.53, pp.1398-1409, oct. 2006.

[17] S.-K. Chung, "Phase-locked loop for grid-connected three-phase power conversion systems," Proc. Inst. Electr. Eng.-Electron. Power Appl., vol. 147, no. 3, pp. 213-219, May 2000.

[18] G. C. Hsieh and J. C. Hung, "Phase-locked loop techniques-A survey," in IEEE Transactions on Industrial Electronics, vol. 43, pp. 609-615, Dec. 1996.

[19] Mutoh, N., Ohno, M., Inoue, T., "A method for MPPT Control while searching for parameters corresponding to weather conditions for PV generation systems", in IEEE Transactions on Industrial Electronics, vol.55, pp.1055-1065, June 2008.

[20] Mutoh, N., Inoue, T., "A control method to charge series connected ultraelectric double layer capacitors suitable for photovoltaic generation systems combining MPPT control method", in IEEE Transactions on Industrial Electronics, vol.54, pp.374-383, feb.2007.

[21] Noguchi, T., Togashi, S., Nakamoto, R., "Short-current pulse-based maximum power point tracking method for multiple photovoltaic and converter module system", in IEEE Transactions on Industrial Electronics, vol.49, pp.217-223, feb. 2002.

[22] Fortunato, M., Giustiniani, A., Petrone, G., Spagnuolo, G., Vitelli, M., "Maximum Power Point Tracking in a One Cycle controlled single stage photovoltaic inverter", in IEEE Transactions on Industrial Electronics, vol.55, pp.2684-2693, July 2008.

[23] Patel, H., Agarwal, V., "Maximum Power Point Tracking Scheme for PV Systems operating under partially shaded conditions", in IEEE Transactions on Industrial Electronics, vol.55, pp.1689-1698, April 2008.

[24] Figueres, E., Garcera, G., Sandia, J., Gonzalez-Espin, F.J., "Dynamic Analysis of Three-phase Photovoltaic Inverters with a High Order Grid Filter", Proceedings of the IEEE International Symposium on Industrial Electronics, ISIE'2007, pp., 2007.

[25] R. W. Erickson and D. Maksimovic, Fundamentals of Power Electronics,2nd ed. Norwell, MA: Kluwer, 2001.

[26] S. Buso and P. Mattavelli, Digital Control in Power Electronics, Ed. Morgan \& Claypool, 2006.

[27] MATLAB ${ }^{\circledR}$ Control System Toolbox. Using the Control System Toolbox (Version 5). The Mathworks Inc. 2000-2001.

[28] Castilla, M.; Miret, J.; Matas, J.; de Vicua, L.G.; Guerrero, J.M. "Linear Current Control Scheme With Series Resonant Harmonic Compensator for Single-Phase Grid-Connected Photovoltaic Inverters", in IEEE Transactions on Industrial Electronics, vol. 55, pp. 2724-2733, july 2008.

[29] Femia, N.; Lisi, G.; Petrone, G.; Spagnuolo, G.; Vitelli, M. "Distributed Maximum Power Point Tracking of Photovoltaic Arrays: Novel Approach and System Analysis", in IEEE Transactions on Industrial Electronics, vol. 55, pp. 2610-2621, july 2008.

[30] Fangrui Liu; Shanxu Duan; Fei Liu; Bangyin Liu; Yong Kang "A Variable Step Size INC MPPT Method for PV Systems", in IEEE Transactions on Industrial Electronics, vol. 55, pp. 2622-2628, july 2008.

[31] Sera, D.; Teodorescu, R.; Hantschel, J.; Knoll, M. “ Optimized Maximum Power Point Tracker for Fast-Changing Environmental Conditions", in IEEE Transactions on Industrial Electronics, vol. 55, pp. 2629-2637, july 2008.

[32] Gules, R.; De Pellegrin Pacheco, J.; Hey, H.L.; Imhoff, J. “A Maximum Power Point Tracking System With Parallel Connection for PV StandAlone Applications" in IEEE Transactions on Industrial Electronics, vol. 55, pp. 2674-2683, july 2008 . 


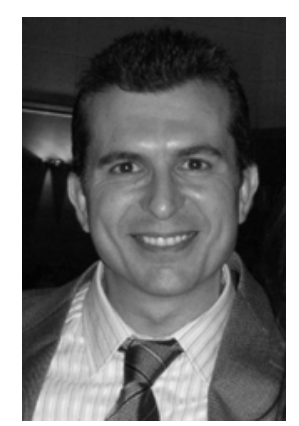

Emilio Figueres (S'97, A'00) received the M.Sc. degree from the Ecole Nationale Superieure d'Electrotechnique, d'Electronique, d'Informatique et d'Hydraulique de Toulouse, Toulouse, France, in 1995 , and the Dr. Ingeniero Industrial (Ph.D.) degree from the Universidad Politecnica de Valencia (UPV), Valencia, Spain, in 2001.

Form 1995 to 1996 he was with the R\&D Departments of the companies GH ELIN International (currently GH Group) and Power Electronics Spain, where he was involved in the design of high performance power electronic converters. Since 1996, he has been with the Electronics Engineering Department, UPV, where he is currently the Department Director and, from 2004 to 2008, has been the Deputy Director for R\&D activities. His main research fields are in modeling and control of power converters, power processing of renewable energy sources, and grid connected converters for distributed power generation and power quality improvement.

Dr. Figueres is a member of the IEEE Power Electronics Society and of the IEEE Industrial Electronics Society.

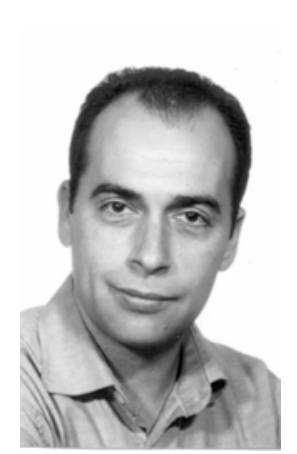

Gabriel Garcerá (S'97, A'99, M’04) received the Ingeniero de Telecomunicación (M.Sc.) and Dr. Ingeniero de Telecomunicación (Ph.D.) degrees from the Universidad Politecnica de Valencia (UPV) in 1993 and 1998, respectively.

From 1993 to 1995 he was with the R\&D Department of the company GH ELIN International (currently GH Group), involved in the design of high current switch-mode power supplies for particle accelerator superconducting magnets. By the end of 1995 he joined the Electronics Engineering Department, UPV, where he is currently an Associate Professor and the Coordinator of the Industrial Electronic Systems Group (GSEI), http://gsei.upv.es. His main research fields are in power converter modeling and control, robust control of switching converters, softswitching energy conversion, power factor correction circuits, uninterruptible power supplies, grid-connected inverters and converters for renewable energy sources.

Dr. Garcerá is a member of the Spanish Association of Telecommunications Engineers. Since 2004, he is an Associate Editor of the IEEE Transactions on Industrial Electronics.

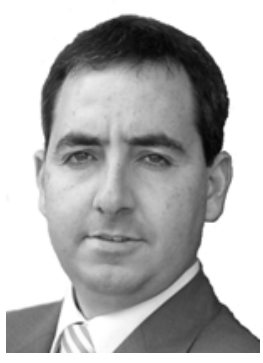

filters.

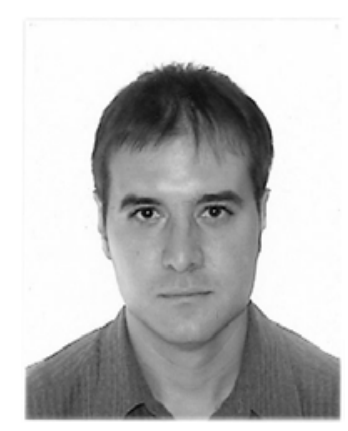

Francisco González-Espín (S’07) was born in Elche, Spain, in 1976. He received the Ingeniero Técnico en Electrónica Industrial (B.S.) and Ingeniero en Automática y Electrónica Industrial (M.Sc.) degrees from the Polytechnic University of Valencia (UPV), Valencia, Spain, in 2002 and 2005, respectively, where he is currently working toward the Ph.D. degree.

From 2004 to 2006, he was with the R\&D Department, VMB Española S.A., Valencia, where he was involved in the design of electroacoustic and powerelectronics audio systems. Since 2006, he has been with the Electronics Engineering Department, UPV, where he was with the Industrial Electronic System Group through a grant from the FPI program of the Spanish Ministry of Science and Technology. His main research fields are power-converter modeling and control, power amplifiers and power supplies for audio systems, and converters for renewable energy sources.

Mr. González-Espin is a Student Member of the IEEE Industrial Electronics Society, IEEE Power Engineering Society, and IEEE Power Electronics Society, as well as of the Audio Engineering Society.

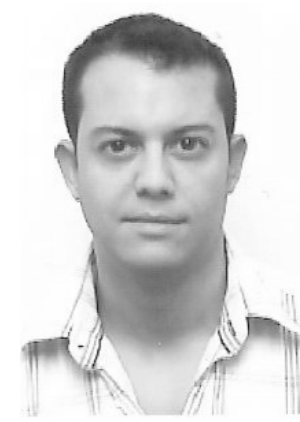

Jesús Calvo Rubio received the B.Eng. degree in electronics and automation engineering from the Universidad Politecnica de Valencia (UPV), Valencia, Spain, in 2002, where he is currently working toward th Ph.D. degree.

Since 2005, he has been with the company Siliken Electronics, involved in the design of power converters for renewable energy sources and managing power electronics projects. His main research interests are in power electronics and control.
Jesús Sandia was Born in Valencia, Spain in 1976. He received the Ingeniero Tecnico Industrial (B.S.) and the Ingeniero Industrial (M.Sc.) degrees in 1999 and 2003, respectively, from the Universidad Politecnica de Valencia (UPV), Valenca, Spain, where he is currently working toward the $\mathrm{Ph} . \mathrm{D}$. degree. Since 2003 he has been with the Electronics Engineering Department, UPV, where he is currently a Laboratory Technician. His main research fields are in power converter modeling and control, power factors correction circuits, and active 